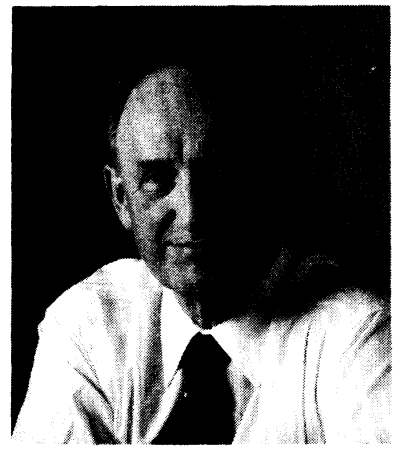

\section{Authors, Members, and Readers}

As you read this editorial, there are a number of truisms that are worth noting:

- All authors are not members.

- All members are not authors.

- All readers are not members.

- All readers are not authors.

- All members are readers.

I have stressed the word member here because as a long-time supporter of SPIE, I would like to make some comments about membership in SPIE-The International Society for Optical Engineering-membership in general and its relationship to Optical Engineering in particular.

Let me start with some information about Optical Engineering and the involvement of members of our society. Please remember that the journal Optical Engineering is a real benefit of being a member. The members support the journal with their dues and hence in a meaningful and deliberate way support the other readers of Optical Engineering who do not subscribe to the journal.

Over the last few years I have collected data on the authorship of the papers that we have published in Optical Engineering (see my various editorials ${ }^{1}$ ). Another part of that data is shown in Table 1, which gives information on the percentage of papers published each year that have at least one author who is a member. The table also shows the percentage of all authors who are members-regular and fellows.

Table 1 shows a declining, but nevertheless healthy, percentage in both categories. This is understandable as we reach out to a wider international authorship, and due to the fact that for some of our international colleagues it is very difficult to pay the membership dues because of the restrictions on the availability of hard or local currency.
Table 1 Member involvement as authors.

\begin{tabular}{|ccc|}
\hline Year & $\begin{array}{c}\text { \% papers with at least } \\
\text { one author/member }\end{array}$ & $\begin{array}{c}\text { \% of all authors } \\
\text { who are members }\end{array}$ \\
\hline 1991 & 66.0 & 33.0 \\
1992 & 57.2 & 29.6 \\
1993 & 53.4 & 24.5 \\
$1994^{\mathrm{a}}$ & 49.3 & 20.4 \\
\hline
\end{tabular}

a Year to date through September issue.

\section{Membership As a Responsibility}

For many of us it becomes a professional responsibility to become a member of professional societies in our discipline. Thus I personally ${ }^{2}$ have five such memberships including SPIE-The International Society for Optical Engineering (since 1964). The professional societies in science and engineering are learned societies that promote the discipline by scholarly publication and meetings. Some of them by tradition are member-driven, societies that are "by, with, and for" the members. That is certainly appropriate. Nearly all societies have some form of outreach to the rest of the technical and business community and welcome nonmembers to their society activities. On a personal note, I became involved with SPIE because I sensed a mission that focused much more on the outreach and the transfer of technology to users who may be in a wide variety of disciplines and whose center of gravity was not located necessarily in optical sciences and engineering.

Members of SPIE attempt to examine, explain, and use optical science or they invent, develop, and implement new 
technologies. That statement perhaps describes the essence of optical engineering and is a philosophical guide to the work of our society including its publication program, which includes your journal Optical Engineering.

I suppose that by talking about the topic of authorship, membership, and readership I am making a pitch for membership-I hope that you, the reader, do not find that inappropriate.

\section{Postscript}

Naturally I would like to reach the utopian dream of all authors and readers being members. But until that time I urge anyone to submit their work for review and possible publication in
Optical Engineering-I assure you the editorial process has no biases. The editors and the members solicit as wide a readership as possible for the informative and authoritative material published in Optical Engineering.

Brian J. Thompson

Editor

'Optical Engineering Vol. 31(2), 197-198; 31(3), 397-398; 32(1), 56; 32(2), 213-214; 33(2), 325-326; 33(3), 669-670.

${ }^{2}$ I do mean personally, i.e., I pay the membership dues and journal subscriptions.

\section{The Value of Membership}

As SPIE gets ready to celebrate its 40th anniversary in 1995, the board of directors has made a commitment to make SPIE the "member society of choice" for people in the optics community. This commitment includes enhancing existing membership benefits for current members and making those benefits known to potential new members.

\section{Benefits of SPIE Membership}

Joining SPIE as a regular member provides you with many benefits including:

- Opportunity to stay informed

- Peer recognition and professional growth

- Association, communication, and networking with colleagues

- Continuing education

- Participation in and contribution to technical community
- Subscription to Optical Engineering, SPIE's monthly journal

- Subscription to OE Reports, SPIE's monthly newspaper

- Exploration of emerging applications and technologies

- Special member rates

The board's commitment has led to the establishment of a membership committee, chaired by Robert Freiberg. This committee met for the first time at the San Diego annual meeting last July and is tasked with promoting the interests of SPIE members and addressing their needs. If you have suggestions or comments about what SPIE can do to enhance your membership, or if you are interested in joining, please contact Randy Bilof at SPIE, 206/676-3290, or send an e-mail message to membership @ spie.org. 


\section{December 1994}

Optics in Ireland

John Hegarty

University of Dublin

Trinity College

Department of Pure and Applied Physics

Dublin 2, Ireland

+353-1-7022019 • +353-1-711759 FAX

Conleth D. Hussey

University of Limerick

Lightwave Technology Research Ctr.

Plassey Pk.

Limerick, Ireland

35261333644 • 35261330316 FAX

February 1995

High Heat Flux Optical Engineering

Ali M. Khounsary

Argonne National Laboratory

Advanced Photon Source, APS 362

Argonne, IL 60439

$708 / 252-3384 \cdot 708 / 252-3222$ FAX

March 1995

Optical Engineering in Ophthalmology

Suganda Jutamulia

Kowa Company, Ltd.

Silicon Valley Office

100 Homeland Court, Suite 302

San Jose, CA 95112

408/441-9300 • 408/441-0537 FAX

Toshimitsu Asakura

Hokkaido University

Research Institute for Electronic Science

Sapporo, 060 Japan

81-11-716-2111 • 81-11-758-3173 FAX

\section{April 1995}

Optics in the Ukraine

Oleg V. Angelsky

Chernovtsy University

Department of Correlation Optics

2 Kosyubinsky Street

274012 Chernovtsy

Ukraine

(03722) 44730 • (03722) 41314 FAX

May 1995

X-Ray/EUV Optics

Richard B. Hoover

NASA Marshall Space Flight Center

ES52 Space Science Center

Huntsville, AL 35812-0001

E-mail: hoover@ssl.msfc.nasa.gov

205/544-7617 • 205/544-5856 FAX

June 1995

Polarization Analysis and Measurement

Dennis H. Goldstein

WL/MNGA

101 West Eglin Boulevard, Suite 280

Eglin AFB, FL 32542

904/882-4636 ext. 2399 904/882-4034 FAX

E-mail: goldstei@eglin.af.mil

David B. Chenault

Naval Research Laboratory

Code 5622, Optical Sciences

4555 Overlook Avenue

Washington, DC 20375-9998

202/767-0390 202/767-6370 FAX

E-mail: chenault@nrlfs1.nrl.navy.mil
Russell A. Chipman

University of Alabama in Huntsville

Physics Department, Optics Building 318

Huntsville, AL 35899

205/895-6417 ext. $318 \quad$ 205/895-6873 FAX

E-mail: chipmanr@email.uah.edu

\section{July 1995}

\section{Optics in Switzerland}

\section{P. K. Rastogi}

Swiss Federal Institute of Technology-Lausanne

Laboratory of Stress Analysis

CH-1015 Lausanne

Switzerland

E-mail: rastogi@elgc.epfl.ch

(021) 6932445 • (021) 6934748 FAX

\section{August 1995}

Photorefractive Nonlinear Optics

Partha P. Banerjee

University of Alabama in Huntsville

Department of Electrical and Computer

Engineering

Huntsville, AL 35899

205/895-6215 ext. $416 \cdot 205 / 895-6880$ FAX

Manuscripts due Jan. 15, 1995

September 1995

Optical Science \& Engineering in Finland

Seppo Honkanen

Nokia Research Center

P.O. Box 45

FIN-00211 Helsinki

Finland

+35804376471・+3580455 2557 FAX

Manuscripts due Jan. 15, 1995

November 1995

Optical Remote Sensing and Image

Processing

Mohammad A. Karim

Bradley D. Duncan

University of Dayton

Center for Electro-Optics

300 College Park

Dayton, OH 45469-0227

$513 / 229-2241 \cdot 513 / 229-3177$

513/229-2471 FAX

Manuscripts due April 1, 1995

\section{December 1995}

Optics in Polymer Science and Technology

Maksymilian Pluta

Institute of Applied Optics

Kamionkowska 18

03-805 Warsaw, Poland

(4822) 184405 • (4822) 133265 FAX

Andrzej Wasiak

Institute of Fundamental Technological Research

Polish Academy of Sciences

Savietokrzyska 2

00-012 Warsaw, Poland

(4822) 269815 FAX

Manuscripts due March 15, 1995.
January 1996

Optical Science and Engineering in Argentina

Guillermo H. Kaufmann

Universidad Nacional de Rosario

Instituto de Fisica Rosario

Applied Optics Group

Bv. 27 de Febrero 210 bis

2000 Rosario

Argentina

E-mail: guille@ifir.edu.ar

or gkaufman@arosario.bitnet

5441825838 • 5441257164 FAX

Manuscripts due June 1, 1995

Visual Communications and Image

Processing

Cheng-Tie Chen

Bellcore, NVC 3X-321

331 Newman Springs Road

Red Bank, NJ 07701

908/758-3106 • 908/758-4371 FAX

E-mail: ctc@nyquist.bellcore.com

Kou-Hu Tzou

COMSAT Laboratories

22300 Comsat Drive

Clarksburg, MD 20871

301/428-4663 • 301/428-9287 FAX

E-mail: kouhu@ctd.comsat.com

Ya-Qin Zhang

GTE Laboratories

40 Sylvan Road

Waltham, MA 02254

617/466-2259 • 617/890-9320 FAX

E-mail: yz00@gte.com

Manuscripts due June 1, 1995

February 1996

Optical Engineering in Small Companies

Xiangyang Yang

Quantex Corporation

2 Research Court

Rockville, MD 20850

301/258-2701 • 301/258-9871 FAX

William J. Miceli

Office of Naval Research

800 North Quincy Street

Arlington, VA 22217-5000

703/696-5752 • 703/696-1330 FAX

Manuscripts due July 1, 1995

March 1996

Sensor Fusion

Belur V. Dasarathy

Dynetics, Inc.

P.O. Box Drawer B

Huntsville, AL 35814-5050

205/922-9230 ext. $355 \cdot 205 / 922-9219$ or

205/922-9260 FAX

E-mail: belur@dynetics.com

Manuscripts due Aug. 1, 1995

May 1996

Optical Engineering in Romania

Adrian Podoleanu

University of Kent at Canterbury

Physics Laboratory

Kent CT2 7NR

United Kingdom

$0227764000 \quad 0227475423$ FAX

E-mail: ap11@ukc.ac.uk

Manuscripts due Sep. 1, 1995 